\title{
The Energetics of Gas Flow and Contact Erosion During Short Circuit Arcing
}

\author{
Paul M. Weaver, Kesorn Pechrach, and John W. McBride
}

\begin{abstract}
The processes governing the movement of short circuit arcs in circuit breakers are complex and variable and the detailed understanding of these processes is incomplete. This paper presents a new approach to our understanding of the short circuit arcing process by concentrating on the bulk thermal behavior and energetics of the arcing and gas flow during contact opening.

It is shown how considerations of the arc power and the heating and vaporization of the contact material can be used to examine the flow of gas through the arc chamber and the erosion of contact material. Experimental data from a flexible test apparatus and arc imaging system along with measurements of pressure and arc current and voltage are used as the basis of the analysis.

It is demonstrated how the air initially present in the arc chamber will be rapidly expelled from the arc chamber to leave an arc burning in the products of contact volatilization. Data on mass and volume flow rates are presented as well as estimates of the gas velocity in the contact region. These data provide information on the nature of the gas flow in the arc chamber as well as contact erosion during the arcing process.
\end{abstract}

Arcing conditions of interest are short circuit faults $\left(10^{3}-10^{4} \mathrm{~A}\right)$ in low voltage (220-380 VAC) circuit breakers.

Index Terms-Arc chamber, arc imaging system, bulk thermal behavior, contact erosion, gas flow.

\section{INTRODUCTION}

$\mathbf{T}$ HE FUNDAMENTAL physics of the short circuit arc are those of highly energetic, strongly coupled magnetically and thermally driven flows of highly ionised plasma. The arc motion in a circuit breaker is complicated and often erratic with a reputation for unpredictability. There is much valuable work going on to obtain better data and to improve modeling techniques to predict and optimize circuit breaker design [1]-[4], [10] but we are a still a long way from fully understanding and predicting the arc dynamics.

Rapid arc mobility in these early stages of contact opening is crucial to successful operation of the circuit breaker. However, this is frustrated by the reluctance of the arc to move in small contact gaps. It is generally held that a minimum contact gap is required for arc motion [5], [6], although the physical mechanism for this is not clear. To reach the minimum contact gap quickly requires very fast contact opening. This requirement drives circuit breaker design and adds cost and complexity to the

Manuscript received September 12, 2002; revised August 15, 2003. This work was supported by the EPSRC and Chugai (USA). This work was recommended for publication by Associate Editor J. J. Shea upon evaluation of the reviewers' comments.

P. M. Weaver is with the Servocell PBT Ltd., Harlow, Essex, U.K. (e-mail pechrach@ soton.ac.uk).

K. Pechrach and J. W. McBride are with the School of Engineering Science, Electromechanical Research Group, University of Southampton, Southampton S017 1BJ, U.K

Digital Object Identifier 10.1109/TCAPT.2004.825787 tripping system. It also restricts the uptake of new technologies such as smart material actuation in these devices.

Recent work [3], [4] has demonstrated how the gas flow and venting arrangements in the arc chamber are a dominant factor in the mobility of the arc. Adverse pressure gradients can counteract the magnetic forces produced by the arc current resulting in arc immobility. It has been proposed [7] that the balance between the gas flow and the magnetic forces on the arc govern arc mobility.

The immobile arc transmits energy to the contacts where it heats, melts, vaporises and ionises the contact material. The resulting gas expands generating a thermally driven flow through the arc chamber. The flow process is inherently complex due to the nature of the fluid and the geometry of the arc chamber. However, by concentrating on the bulk energetics of the arcing process it is possible to estimate parameters relating to gas flow and arc erosion in the contact region during the initial stages of arc motion.

This paper therefore presents a new approach that considers the thermodynamics of the energy transfer from the arc to the gas. The resulting relations are applied to experimental data on the arc motion and electrical properties to obtain data on the gas flow properties in the contact region as well as contact erosion.

The focus of this work is on the current and voltage ranges typical of miniature circuit breakers used in domestic, commercial and light industrial applications. These low cost mass produced devices typically operate with short circuit currents in the range $10^{3}-10^{4} \mathrm{~A}$ and voltages up to $250 \mathrm{~V}$ ac.

\section{ENERgy AND Gas Flow In the Contact AREA}

The period of reduced arc motion is characterized by a relatively short arc. Much of the arc energy is transmitted to the contacts where it heats, melts, vaporises and ionizes the contact material.

The arc current and voltage and therefore the power and energy inputs into the system are easily measured and well quantified. A complex process then transforms this energy primarily into expulsion of the exhaust gases and heat in the metal parts of the circuit breaker. Both of these can be investigated by relatively simple consideration of the bulk energetics of the gas and other materials. Particularly during the early stages of arc motion in the contact region the generation of metal vapor is a key part of the process.

We are mainly interested in the bulk gas flow and energy and not in the details of the plasma interactions and small scale flow characteristics. We also do not aim for a highly accurate model of the system, but for an order of magnitude calculation that gives estimates of the key parameters in the process and their 
interactions. To achieve this a number of simplifying assumptions are made.

- The air that initially fills the arc chamber is rapidly expelled so that in a very short time the arc chamber is filled predominantly with metal vapor. We assume therefore that the gas generated by the arc comprises purely metal vapor. This assumption will be supported by the calculation.

- While the arc is in the contact region the vapor is assumed to be silver. In fact the contact system will have some copper parts. The omission of copper will make some difference to the calculation mainly due to the lower atomic weight-approximately $60 \%$ that of Silver. Assuming a $50 \%$ split this would cause a $20 \%$ error which is compatible with the order of magnitude assessment we are aiming for here. To a lesser degree some Carbon will be produced from the graphite loading in the contacts and some breakdown products from plastic parts will also be present. These are not likely to play a significant part in the bulk thermal processes and are therefore neglected.

- Although within the arc itself and at the arc roots ionization plays a significant part in the gas dynamics, the exhaust gases cool rapidly to temperatures $<5000 \mathrm{~K}$ [8]. Ionization will therefore play only a small part in the energetics of the flow through the contact region and into the bulk of the chamber and is therefore neglected.

- The gas is assumed to behave as an ideal monatomic gas which under the conditions of interest should be sufficiently accurate.

- The expansion of the gas is assumed to occur under constant pressure. Measurements of the gas pressure in the arc chamber show only moderate pressure rises and therefore support this assumption.

The total enthalpy of the metal vapor is obtained assuming the following stages.

Stage 1: The metal is heated to melting point.

The specific heat capacity of silver metal in the solid phase, $c_{\mathrm{ps}}$, varies slightly with temperature $\mathrm{T}$ and is given by [9]

$$
c_{p s}=A+B T+C T^{2}+D T^{-2} .
$$

The coefficients A, B, C, and D for solid and liquid phases are given in Table I.

For silver the melting temperature $T_{m}$ is $1235 \mathrm{~K}$. It is assumed that the starting temperature $T_{s}$ is $298 \mathrm{~K}$. The enthalpy change, $\Delta h$, of the metal heated from the starting temperature to the melting point is given by

$$
\Delta h=\int_{T_{s}}^{T_{m}} c_{p s} d T=245 \mathrm{~kJ} \mathrm{~kg}^{-1} .
$$

Stage 2: Melting the metal. The enthalpy of fusion for $\mathrm{Ag}$ is $102 \mathrm{~kJ} \mathrm{~kg}^{-1}$.

Stage 3: Heat the liquid. The specific heat capacity $c_{p l}$ of the liquid metal does not vary with temperature as shown in Table I [9] and is equal to $283 \mathrm{~J} \mathrm{~kg}^{-1} \mathrm{~K}^{-1}$. The boiling temperature, $T_{b}$, is $2400 \mathrm{~K}$. The enthalpy change to heat the liquid to boiling point is given by

$$
\Delta h=c_{p l}\left(T_{b}-T_{m}\right)=330 \mathrm{~kJ} \mathrm{~kg}^{-1} \text {. }
$$

TABLE I

COEFFICIENTS OF A, B, C, AND D

\begin{tabular}{l|l|l|l}
\hline & Solid & Liquid & \\
\hline A & 197 & 282 & $\mathrm{~J} \mathrm{~mol}^{-1} \mathrm{~K}^{-1}$ \\
\hline B & $79.1 \times 10^{-3}$ & 0 & $\mathrm{~J} \mathrm{~mol}^{-1} \mathrm{~K}^{-2}$ \\
\hline C & 0 & 0 & $\mathrm{~J} \mathrm{~mol}^{-1} \mathrm{~K}^{-3}$ \\
\hline D & $1.40 \times 10^{6}$ & 0 & $\mathrm{~J} \mathrm{~mol}^{-1} \mathrm{~K}$ \\
\hline
\end{tabular}

Stage 4: Boil the liquid. The enthalpy of vaporization is $2362 \mathrm{~kJ} \mathrm{~kg}^{-1}$.

Stage 5: Heat the gas. The specific heat capacity at constant pressure for a perfect monatomic gas is $20.8 \mathrm{~J} \mathrm{~mol}^{-1} \mathrm{~K}^{-1}$. Silver has an atomic weight of $108 \mathrm{~g} \mathrm{~mol}^{-1}$. The specific heat capacity of the vapor, $c_{p l}$, is therefore $193 \mathrm{~J} \mathrm{~kg}^{-1} \mathrm{~K}^{-1}$. The enthalpy change for heating the gas to a final temperature $T_{g}$ is given by

$$
\Delta h=c_{p l}\left(T_{g}-T_{b}\right) .
$$

For a final gas temperature of $4000 \mathrm{~K}$ the enthalpy change would be $308 \mathrm{~kJ} \mathrm{~kg}^{-1}$.

The total enthalpy change is given by the sum of the individual processes

$$
\begin{aligned}
\Delta h= & \int_{T_{s}}^{T_{m}} c_{p s} d T+\Delta h(\text { melting }) \\
& +\int_{T_{m}}^{T_{B}} c_{p l} d T+\Delta h(\text { vaporization })+\int_{T_{B}}^{T_{G}} c_{p} d T .
\end{aligned}
$$

The contributions to the total enthalpy change for these process are summarized in Fig. 1, assuming the gas is heated to $4000 \mathrm{~K}$.

It is clear that the enthalpy change is dominated by the enthalpy of vaporization. Because of this the enthalpy change does not vary significantly with the final gas temperature Fig. 2 .

It is therefore not necessary to know exactly the final gas temperature and a working figure of $4000 \mathrm{~K}$ is used in these calculations.

The arc power, $\mathrm{W}$, is the product of the instantaneous arc current (I) and voltage (V)

$$
W(t)=I(t) \cdot V(t) .
$$

Most of the power will heat the material through every stage described above to produce heated gas. It is therefore assumed that the arc power $W$ is all used to melt the contact material and produce $\mathrm{Ag}$ gas at constant pressure

$$
\begin{aligned}
W(t)= & \Delta h \frac{d m}{d t} \\
W(t)= & \left(\int_{T_{s}}^{T_{m}} c_{p s} d T+\Delta h(\text { melting })\right. \\
& \left.+\int_{T_{m}}^{T_{B}} c_{p l} d T+\Delta h(\text { boiling })+\int_{T_{B}}^{T_{G}} c_{p} d T\right) \frac{d m}{d t}(7)
\end{aligned}
$$




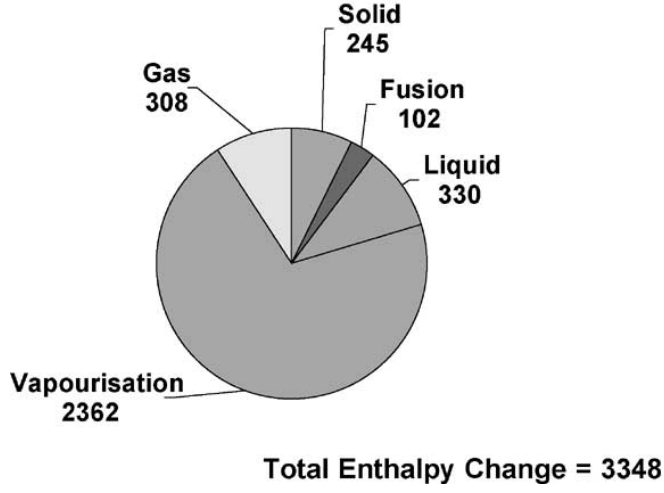

Fig. 1. Contributions to the enthalpy change in contact vaporization in $\mathrm{kJ} \mathrm{kg}^{-1}$.

where $d m / d t$ is the mass flow rate from the contacts. The density of the $\mathrm{Ag}$ gas is obtained from

$$
\frac{P}{\rho_{A g}}=R_{A g} \cdot T \text {. }
$$

Again an assumption is required about the temperature of the gas. Due to the direct dependency of the density on the temperature, this assumption will affect the estimate of gas volume flow rates. A figure of $4000 \mathrm{~K}$ is used here for the temperature in the contact region based on previous measurements under similar conditions [8]. This gives the volume flow rate as

$$
\frac{d V}{d t}=\frac{1}{\rho_{A g}} \cdot \frac{d m}{d t} .
$$

This can be converted to an average flow velocity by assuming a channel cross-sectional area, A

$$
v_{\text {fluid }}=\frac{1}{A} \cdot \frac{d V}{d t} .
$$

\section{EXPERIMENTAL METHODS}

Short circuit tests were carried out using a flexible test apparatus (FTA) designed to simulate the current limiting operation of a miniature circuit breaker. Full information on the test system, experimental parameters and the methods for evaluating the arc root motion has been presented previously [1]-[4], [10]. Schematic diagrams of the FTA and associated instrumentation are shown in Figs. 3 and 4.

For the experiments presented here, the anode was on the moving contact and the cathode was on the fixed contact. Unless otherwise stated the fixed contact was a $0.8-\mathrm{mm}$ thick $\mathrm{Ag} / \mathrm{C}$ (95/5\%) step, the arc runner was 1-mm thick copper and the arc chamber material was ceramic. The arc chamber vent was choked and the gap behind the moving contact was open.

Arc voltage and arc current profiles were recorded by a digital storage oscilloscope. A high speed arc imaging system (AIS) was used to record the arc motion. The system monitors the arc motion at a sample rate of 1000000 images per second. The optical data provided measurements of durations of reduced arc motion on the contacts.

The pivoting contact mechanism was controlled to allow a range of opening velocities from $1 \mathrm{~m} \mathrm{~s}^{-1}$ to $10 \mathrm{~m} \mathrm{~s}^{-1}$. The contact position was recorded by intensity sensitive photo sensors.

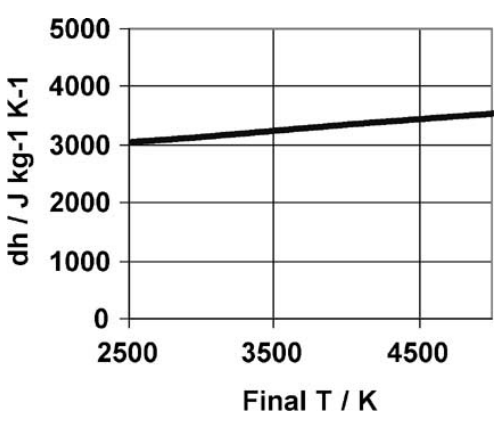

Fig. 2. Effect of final gas temperature on the enthalpy change for contact vaporization.

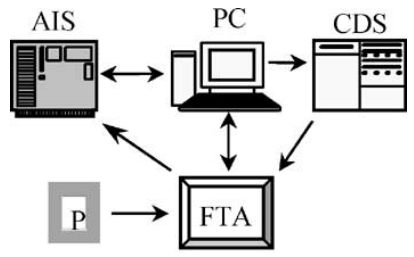

AIS : Arc Imaging System FTA : Flexible Test Apparatus CDS : Capacitor Discharge System $\mathrm{P}$ : Pressure Transducer

Fig. 3. Experimental configuration

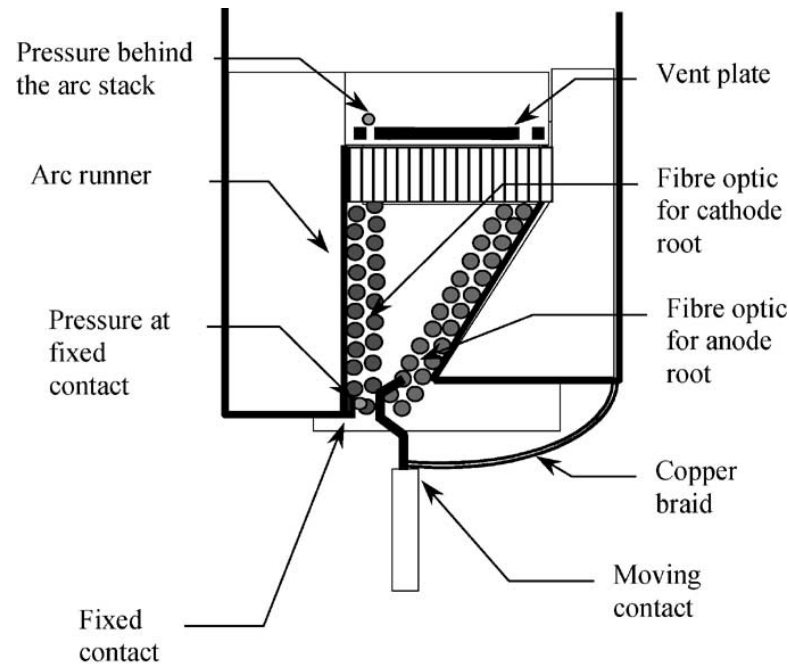

Fig. 4. Schematic of the flexible test apparatus

Pressure transducers were used to measure gas pressure in the arc chamber [2]-[4], [10].

\section{RESUlTS AND DisCUSSION}

Pressure measurement results in the arc chamber are shown in Fig. 5 along with optical data showing the arc root trajectories on the anode (moving contact) and cathode (fixed contact).

The pressure measurements show that under these conditions the pressure rise in the arc chamber is not very great. The pressure in the contact region does not rise over 0.1 bar above ambient. This justifies the assumption behind the use of the enthalpy in Section II that the gas expansion is approximately at constant pressure. 


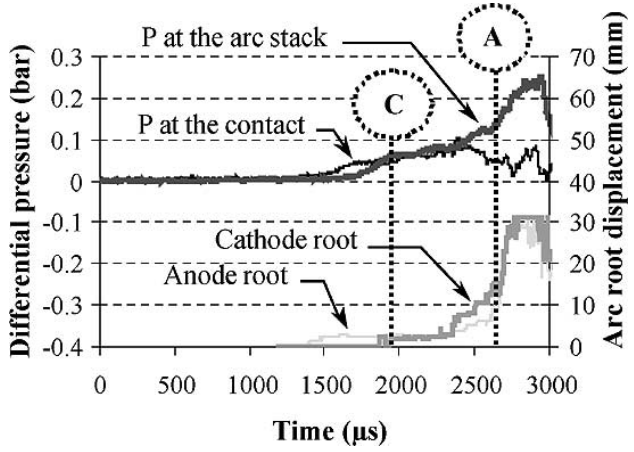

Fig. 5. Arc root displacement and differential pressure in the arc chamber. Point "A" is the point at which the anode root moves from moving contact and point " $\mathrm{C}$ " is the point at which the cathode root moves from fixed contact (contact velocity $1 \mathrm{~ms}^{-1}$, polycarbonate arc chamber, $\mathrm{Ag} / \mathrm{C}$ flat).

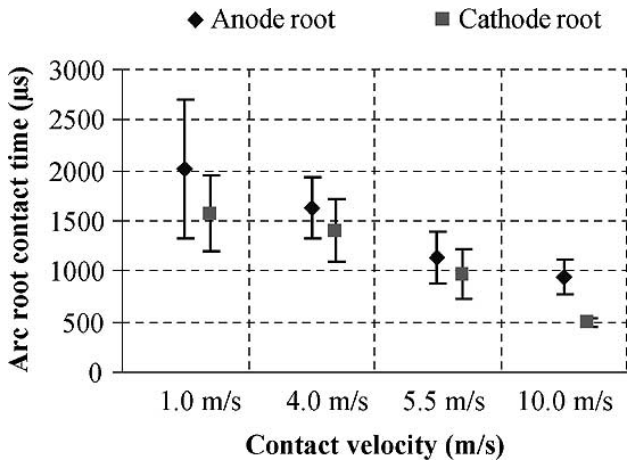

Fig. 6. Cathode and anode root contact times as a function of contact opening velocity.

The points at which the anode and cathode start to move are obtained from the optical data and marked as A and C, respectively on Fig. 5. Although the cathode moves slightly at point C its velocity remains very low for a significant time afterwards. This is most likely due to the arc root crossing the edge of the contact. The cathode could therefore be considered to be in the contact region for nearly as long as the anode, i.e., up to point A.

The arc root contact times measured in the same way for various contact opening velocities are shown in Fig. 6.

Again the upper (anode root) value can be assumed as the period that the arc is in the contact region.

Typical current and voltage recordings from the flexible test apparatus are shown in Figs. 7 and 8. The arc power is calculated as the product of the arc voltage and current [see (6)]. Results are shown in Fig. 9.

Equation (7) is used to calculate the mass flow rate from the contact region. Results are shown in Fig. 10.

Integration of the mass flow rate yields an estimate of the cumulative mass of gas produced during the arcing process. This is shown for the period of while the arc is in the contact region in Fig. 11.

The total mass evaporated from the contact while the arc is in the contact region (i.e. up to the anode time given in Fig. 6) as a function of contact velocity is shown in Fig. 12.

As expected there is significantly more contact material removed for lower contact velocities than at higher velocity.

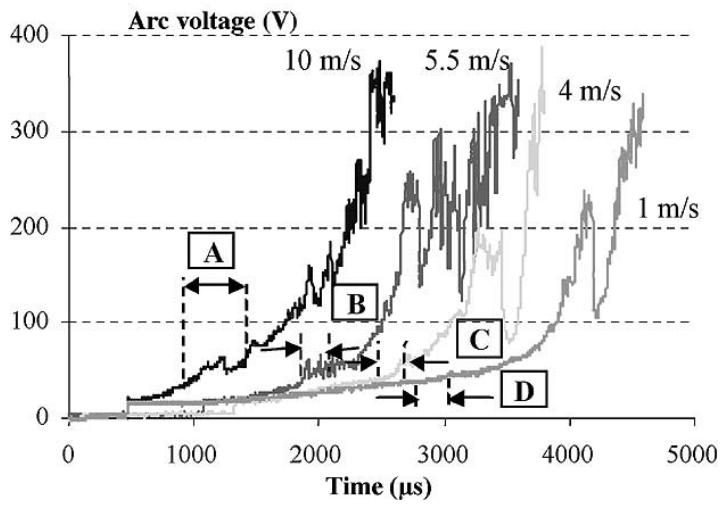

Fig. 7. Arc voltage variation with contact opening velocity. A, B, C, and D show the times at which the cathode root moves (start) and when the anode root moves (end) from the contact region.

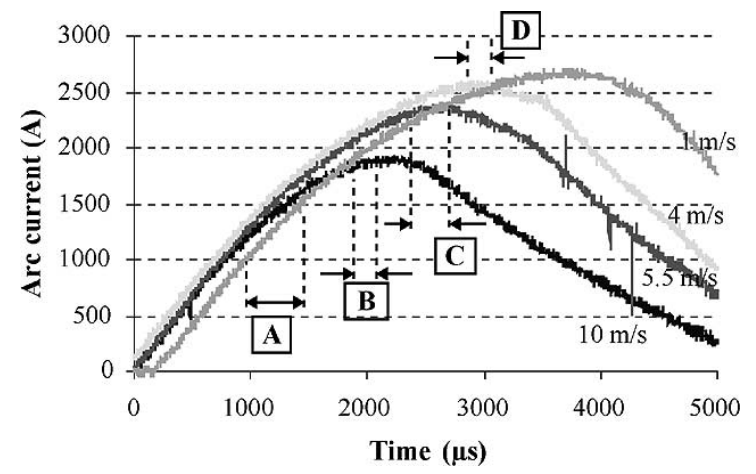

Fig. 8. Current recordings at different contact opening velocities. A, B, C, and $\mathrm{D}$ indicate the times when the cathode root moves (start) and when the anode root moves (end) from the contact region.

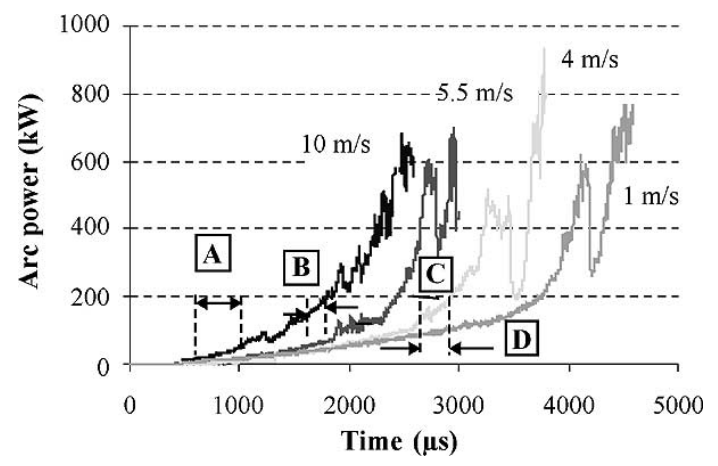

Fig. 9. Variation of arc power with contact opening velocity. A, B, C, and D are the times when the cathode root moves (start) and when the anode root moves (end) from the contact region.

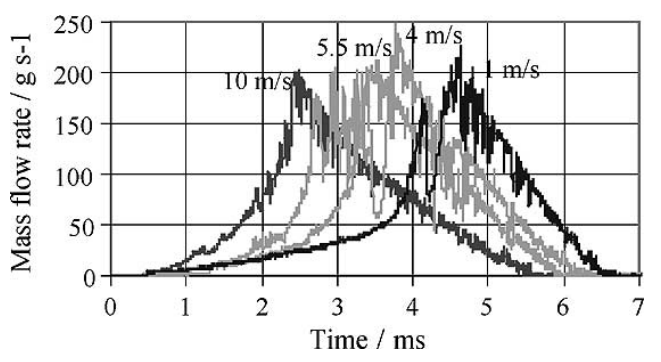

Fig. 10. Mass flow rates for contact velocities of 10, 5.5, 4, and $1 \mathrm{~m} \mathrm{~s}^{-1}$. 


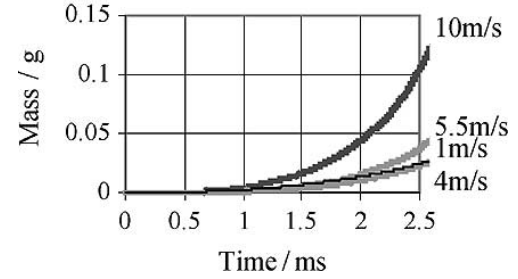

Fig. 11. Cumulative mass evolution for contact velocities of 10, 5.5, 4, and $1 \mathrm{~m} \mathrm{~s}^{-1}$.

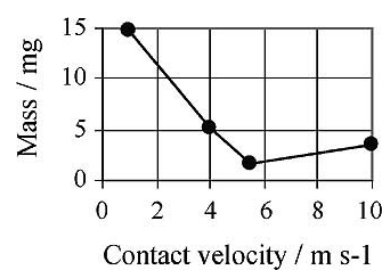

Fig. 12. Total mass evolved up to anode root movement for contact velocities of $10,5.5,4$, and $1 \mathrm{~m} \mathrm{~s}^{-1}$.

The calculations used for Fig. 11 are based on assumptions for conditions in the contact region which will not be directly applicable as the arc starts to move. A larger proportion of the arc energy will still be used to heat the steel arc splitters as well as vaporising the arc chamber materials. Also, the electrode materials will be copper and steel when the arc has moved off the contacts. While these factors will affect the accuracy of the results the total mass is still a useful indicator as an upper limit of the material that could be removed from the contacts and is shown in Fig. 13.

It is interesting to note that the total mass (this is related to the arc energy) does not vary significantly with contact velocity. This is because the arc power during the period in the contact region is low compared to the arc power as the arc runs into the splitter plates. This period is longer for lower contact velocity, but the contribution of this period to the total energy is quite small, The higher current when the arc does move leads to a faster reduction in current and therefore a lower energy dissipated in the arc stack. This more than compensates for the extra energy dissipated in the contact region. This balance between the energy dissipated in the contact region and that dissipated in the arc stack is an important factor in contact erosion and the energy handling capacity of the breaker. A breaker operating at lower contact velocity may therefore need more contact material, but a smaller arc stack.

The volume flow rates calculated from (9) are shown in Fig. 14 for the period when the arc is in the contact region.

A typical volume flow rate would be around $300 \mathrm{~cm}^{2} \mathrm{~ms}^{-1}$. The channel cross section is of the order $0.3 \mathrm{~cm}^{2}$ giving an estimate for the gas velocity of the order of $10 \mathrm{~m} \mathrm{~s}^{-1}$. This gas velocity is sufficiently low to produce only moderate pressure changes in the gas flow, in agreement with the measurements reported in Fig. 5.

The cumulative volume of gas produced during the same period is shown in Fig. 15 while the volume at the point of anode root movement is shown in Fig. 16.

Naturally these data show the same functionality as the mass data as they are based on the same power measurements.

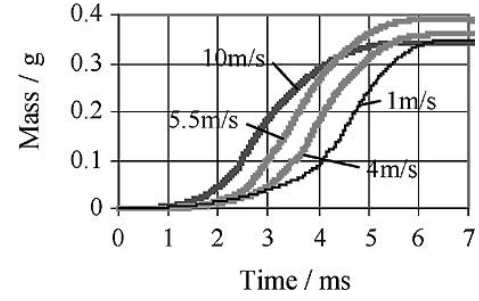

Fig. 13. Total mass produced for contact velocities of $10,5.5,4$, and $1 \mathrm{~m} \mathrm{~s}^{-1}$.

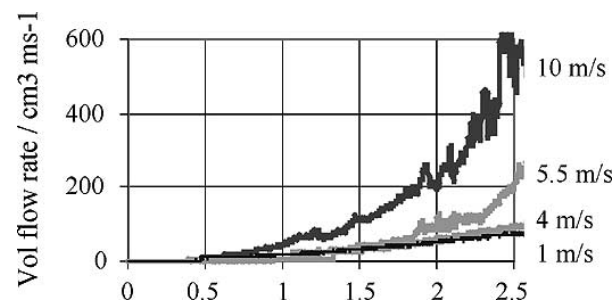

Fig. 14. Volume flow rate in the arc chamber for contact velocities of 10, 5.5, 4 , and $1 \mathrm{~m} \mathrm{~s}^{-1}$.

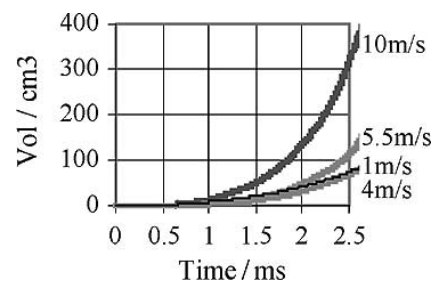

Fig. 15. Cumulative gas volume for contact velocities of 10, 5.5, 4, and $1 \mathrm{~m} \mathrm{~s}^{-1}$

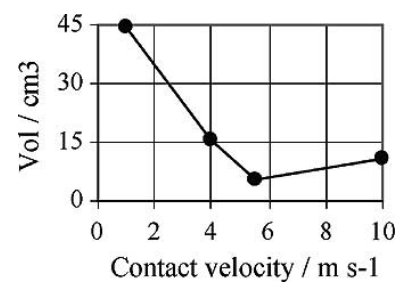

Fig. 16. Total volume evolved up to anode root movement for contact velocities of $10,5.5,4$, and $1 \mathrm{~m} \mathrm{~s}^{-1}$.

The figure for the gas volume evolved while the arc is in the contact region is interesting because it allows us to estimate the composition of the gas. The volume of the contact region itself is of the order of $1 \mathrm{~cm}^{3}$. The air that initially occupies the arc chamber will be rapidly replaced by the vapor from the contacts. Fig. 16 shows that even at high contact velocities more than $5 \mathrm{~cm}^{3}$ of gas will be produced from the contacts. There is unlikely to be a significant quantity of air left in the contact region for most of this period. This justifies the assumption that the gas flow in the contact region is primarily Ag vapor. However, particularly at higher contact velocities, the arc will be moving into an arc chamber that contains air, and this may modify both the arc properties and the gas composition.

The cumulative gas evolved during the arcing period is shown in Fig. 17. As stated previously this result can only be considered very tentative as many of the assumptions that apply while the arc is in the contact region break down as the arc moves into the splitter plates. 


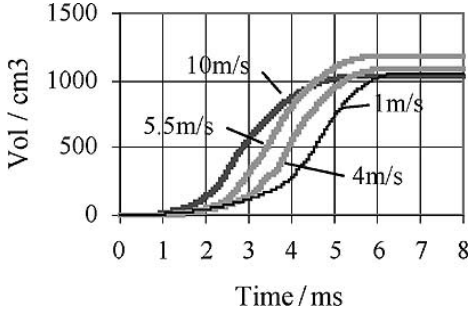

Fig. 17. Total gas volume produced for contact velocities of $10,5.5,4$, and $1 \mathrm{~m} \mathrm{~s}^{-1}$.

\section{CONCLUSION}

1) A new semi-empirical approach to the analysis of events in the contact region is developed using the energy transfer in the contact region to calculate parameters of the gas flow in the arc chamber.

2) The variation of these parameters with contact opening velocity is studied using arc motion, pressure and electrical data obtained from a flexible test apparatus.

3) It is shown that the air initially present in the arc chamber is rapidly expelled from the contact region. At the point of arc motion the arc burns predominantly in metal vapor from contact vaporization.

4) Volume flow rates of around $300 \mathrm{~cm}^{2} \mathrm{~ms}^{-1}$ are predicted while the arc is in the contact region. The estimated gas velocity while the arc is in the contact region was of the order of $10 \mathrm{~m} \mathrm{~s}^{-1}$.

5) The gas velocity is sufficiently low to produce only moderate pressure changes in the gas flow, in agreement with the reported pressure measurements.

6) The mass erosion of the electrodes during arc immobility is calculated as a function of contact opening velocity. As expected a reduction in contact velocity leads to increased erosion.

7) The flow rate calculations can be used as the input to a model of the gas flow in the arc chamber to investigate the effects of arc chamber geometry and venting on the arc dynamics. This is an item for future work.

\section{REFERENCES}

[1] J. W. McBride and P. M. Weaver, "Review of arcing phenomena in low voltage current limiting circuit breakers," Proc. Inst. Elect. Eng., vol. 148, no. 1, pp. 1-7, Jan. 2001.

[2] J. W. McBride, K. Pechrach, and P. M. Weaver, "Arc root commutation from moving contacts in low voltage devices," IEEE Trans. Comp. Packag. Technol., vol. 24, pp. 331-336, Sept. 2001

[3] K. Pechrach, J. W. McBride, and P. M. Weaver, "Gas flow and composition effects on arc motion in current limiting circuit breakers," in Proc. 47th IEEE Holm Conference on Electrical Contacts, Montreal, QC, Canada, Sept. 2001, pp. 12-17.

[4] - "Analysis of arc root mobility in low contact opening velocity circuit breakers," in Proc. 21st ICEC/ITK 2002 Interconference on Electrical Contacts, Zurich, Switzerland, Sept. 2002.

[5] W. Rieder, "Interaction between magnet-blast arcs and contacts," in Proc. 28th Holm Conference on Electrical Contact, Chicago, IL, 1982, pp. 3-10.

[6] E. M. Belbel and M. Lauraire, "Behavior of switching arc in low-voltage limiter circuit breaker," IEEE Trans. Comp., Hybrids, Manufact. Technol., vol. 8, pp. 3-12, Mar. 1985.
[7] E. Belbel and L. Siffroi, "Immobility duration of electric arcs between contactor poles at breaking instant," Electrical Contact, pp. 168-170, 1982.

[8] P. M. Weaver and J. W. McBride, "Conductance measurements in the investigation of short circuit arcs, in miniature circuit breakers," in Proc. 41st IEEE Holm Conference on Electrical Contacts, Montreal, QC, Canada, Oct. 1995, pp. 186-193.

[9] S. Allard, Ed., "International tables of selected constants," in Metals: Thermal and Mechanical Data. New York: Pergamon, 1969, vol. 16.

[10] J. W. McBride, K. Pechrach, and P. M. Weaver, "Arc root commutation from moving contacts in low voltage devices," in Proc. 46th IEEE Holm Conference on Electrical Contacts, Piscataway, NJ, 2000, pp. 130-138.

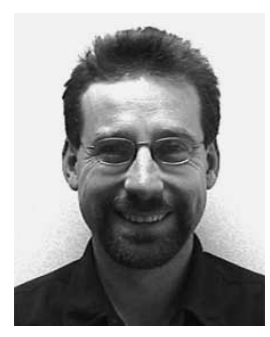

Paul M. Weaver received the B.A. degree (with honors) in natural science from the University of Cambridge, Cambridge, U.K. and the Ph.D. degree in aeronautical engineering from the University of Southampton, Southampton, U.K.

$\mathrm{He}$ is a Research Manager at PBT Ltd, Essex, U.K. (a manufacturer and developer of piezo actuators and circuit protection devices). He has been working in industry since 1993 in research and development of circuit breakers and related switching systems and has published widely in this field. Prior to this he was a Research Fellow at Southampton University researching short circuit arc phenomena. Research interests include switching arc phenomena, smart materials actuation and sensor technologies.

Dr. Weaver is a Member of the IEE.

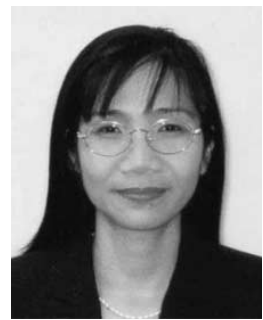

Kesorn Pechrach received the B.Eng. degree in electrical engineering from the Khonkaen University, Khonkaen, Thailand, in 1992, the M.Eng. degree in energy technology from the King Mongkut's University of Technology, Thonburi, Thailand, in 1997 , and is currently pursuing the $\mathrm{PhD}$. degree in the Electro-Mechanical Research Group, University of Southampton, Southampton, U.K.

She has worked for consulting engineer companies as a Lead Electrical Engineer since 1992. Her responsibilities included the design and engineer supervision of electrical facilities for industrial plants, commercial building, roadways, refineries, and $\mathrm{HV}$ substations.

Dr. Pechrach is a Chartered Electrical Engineer of the Engineering Institute of Thailand and a Member of the IEE.

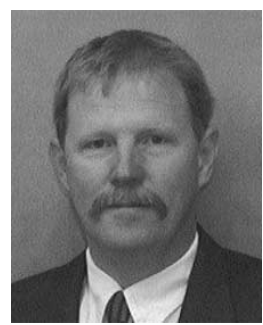

John W. McBride received the M.S. degree in aeronautical engineering from the University of Southampton, Southampton, U.K., in 1978 and the $\mathrm{Ph} . \mathrm{D}$. degree in electrical contact phenomena from Plymouth University, Plymouth, U.K., in 1986.

From 1985 to 1987, he lectured in the Mechanical Engineering Department, Plymouth University, and since 1987, has been a Lecturer, Senior Lecturer, and a Reader in instrumentation and measurement in the School of Engineering Science and the Electrical Engineering Department, University of Southampton. Since 2001, he has been Professor of electromechanical engineering in the School of Engineering Science. He is Chair of the Electromechanical Research Group, and Deputy Head of the School. His main research interests include electrical contacts, metrology, and instrumentation.

Dr. McBride is an Associate Editor of the IEEE TRANSACTIONS ON COMPONENTS AND PACKAgING TeChNologies, a Chartered Engineer, and Chair of the Electro-Mechanical Research Group, and Vice Chair of IEE Professional Group S3 Electron Physics, Plasmas, and Applications. He is a Member of the Organizing Committee, IEEE Holm Conference on Electrical Contacts. 